\title{
PENGELOLAAN LAHAN BERBASIS BUDAYA LOKAL DI SUB DAS ANTOKAN KABUPATEN AGAM
}

\author{
FIRMAN HIDAYAT ${ }^{1}$, RIZKI SAPUTRA ${ }^{2}$ DAN, TEGUH HARIA ADITIA PUTRA ${ }^{3}$ \\ Universitas Muhammadiyah Sumatera Barat \\ Jln. Pasir Kandang No. 4 Koto Tangah, Padang \\ *Corresponding Author: firman.hidayat1961@gmanil.com
}

\begin{abstract}
ABSTRAK
Masalah yang dihadapi didalam pengelolaan Daerah Aliran Sungai (DAS) saat ini adalah peningkatan jumlah penduduk. Peningkatan jumlah penduduk berakibat pada peningkatan kebutuhan akan lahan. Sekitar 24.013,76 ha DAS Antokan terancam kritis (BPDASHLAK.2015). Hal ini disebabkan oleh dibangunnya pemukiman, dan adanya penebangan pohon secara ilegal. Tujuan penelitian adalah untuk mengetahui prediksi tekanan penduduk, tingkat kesejahteraan penduduk, dan mengetahui ada atau tidaknya suatu sistem pengolahan lahan. Penelitian ini dilakukan pada tahun 2018 di sub-DAS Antokan Kecamatan Tanjung Raya Kabupaten Agam. Metode penelitian yang digunakan untuk tekanan penduduk (TP) dan sistem pengolahan lahan secara konservasi yang mengacu pada Peraturan Dirjen RLPS No : P.04/V-SET/2009, untuk TP analisis yang digunakan adalah $\quad \mathrm{TP}=z \frac{f . P o .(1+r){ }^{t}}{L}$ sedang untuk pengolahan lahan secara konservasi analisisnya adalah untuk tingkat kesejahteraan penduduk (TKP) dengan analisis untuk kategori kk miskin adalah \% KK miskin $=\frac{\text { jumlah KK miskin }}{\text { jumlah KK total }} \times 100 \%$, untuk kategori ratarata pendapatan analisisnya adalah rata-ratapendapatan $=\frac{\text { total pendapatan }}{\text { jumlah penduduk }}$. Berdasarkan hasil penelitian diperoleh hasil untuk TP adalah 2,507 dengan klasifikasi TP $>2$ dengan kelas Jelek . Tingkat kesejahteraan penduduk untuk kk miskin adalah 13,8 \% dengan klasifikasi nilai $10<\mathrm{TKP} \leq 20$ dan kelas Sedang, sedang untuk rata-rata pendapatan adalah Rp 9.550.000,-/orang/tahun dengan klasifikasi nilai TKP $>5$ juta dan kelas Sangat Baik. Sistem pengolahan lahan secara konservasi diklasifikasikan dengan nilai Ada dipraktekkan dengan baik dan kelas Sangat Baik.
\end{abstract}

Kata Kunci: konsumsi, kritis, prediksi, konservasi, klasifikas

\section{ABSTRACT}

The problem of watersheds management currently faced increasing the number of population and needed for land. Due to the construction of settlements, and illegal logging, around 24,013.76 ha of the Antokan watershed management have been decreasing. The research objectives to determine the prediction of population pressure, level of population welfare, and to determine the system tillage of cultivation. This research was conducted in 2018 in the Antokan sub-watershed, Tanjung Raya District, Agam Regency. The research the method used for population pressure and land management systems in a conservation manner refers to the Regulation of the DirectorGeneral of RLPS No: P.04/V-SET/ 2009, for TP analysis used is TP $=\mathrm{z}$ (f.Po. (1) $+\mathrm{r}$ ) $[\wedge t \rrbracket) / L$ is for land management in a conservation way, the analysis for the level of population welfare (PW) refers to the Indonesian Ministry of Environment and Forestry, category of poor families is a poor family $=$ (number of poor families)/(total number of households) $\times 100 \%$, for the average income category, the average of income $=$ (total income)/(number of population). Based on the research results, the population pressure 
was 2.507 with value $>2$ classifications with the poor class. The welfare level of the population for poor families is $13.8 \%$ with a value classification of $10<\mathrm{TP} \leq 20$ and moderate class, while the average income is IDR 9,550,000/person/year with a classification of PW value $>5$ million and very classy. organized Conservation management systems are classified by categories well-practiced and Very Good.

Keywords: consumption, critical, prediction, conservation, classification

\section{PENDAHULUAN \\ Latar Belakang}

Pembukaan lahan hutan secara besar-besaran dapat menimbulkan banyak kerusakan dan permasalahanpermasalahan baru khususnya di kawasan hutan maupun kerusakan pada kondisi lingkungan seperti erosi tanah, banjir, kekeringan, kepunahan ekosistem, dan terjadi perubahan iklim global yang sangat cepat. Fenomena banjir dan kekeringan serta sedimentasi di sepanjang badan sungai merupakan permasalahan utama pada pengelolaan sumberdaya air di hampir semua wilayah sungai. Upaya selama ini lebih diutamakan pada penyelesaian di hilir dari keseluruhan sistem sungai dan lebih pada aspek fisik. Upaya konservasi sumberdaya air belum secara optimal melibatkan masyarakat, dan sebagaimana diketahui bahwa aktivitas manusia lebih dominan sebagai penyebab timbulnya permasalahan tersebut (Guntoro 2008).

Tingginya tekanan penduduk terhadap lahan pertanian pada suatu DAS dapat memicu terjadinya alih fungsi lahan pertanian menjadi non pertanian dan pemanfaatan lahan yang tidak sesuai dengan kelas kemampuan lahannya sehingga menyebabkan terjadinya degradasi sumber daya lahan dan menyebabkan kesehatan DAS terganggu yang tercermin dari kerusakan ekosistem pada suatu DAS (Jones et. al., 2002, Agus U \& Pranatasari D.S, 2015).

Chomitz et al., (2006) mengemukakan bahwa terdapat hubungan yang erat antara degradasi lahan, sistem hidrologi, dan kemiskinan di dalam DAS. Terganggunya sistem hidrologi DAS menjadi salah satu penyebab terjadinya degradasi lahan yang pada akhirnya berdampak pada tingkat kesejahteraan masyarakat di lingkungan DAS, yaitu terjadinya kemiskinan dan penurunan pendapatan petani.

Tingkat pendapatan petani yang rendah akan mempengaruhi pengeluaran dan pola konsumsi rumah tangga. Semakin besar tingkat pendapatan seseorang, biasanya akan diikuti dengan tingkat konsumsi yang tinggi, sebaliknya tingkat pendapatan yang rendah akan diikuti dengan tingkat konsumsi yang rendah pula.

Keberadaan sistem pengolahan lahan secara konservasi dapat memberi manfaat yang besar terhadap manusia. Dari segi ekologi, sistem pengolahan lahan secara konservasi dapat mencegah terjadinya erosi dan banjir, sedang dari segi ekonomi sistem ini dapat menambah pendapatan petani baik dari hasil buah maupun dari hasil lainnya.

Sekitar 24.013,76 ha DAS Antokan terancam kritis. Rusaknya sungai yang berhulu di danau Maninjau dan hilir di kecamatan Tanjung Mutiara disebabkan karena dibangunnya pemukiman, dan adanya penebangan pohon secara ilegal. Apabila tidak diselamatkan maka lahan tersebut akan semakin kritis dan akan berdampak pada hilangnya mata pencaharian masyarakat di sekitar DAS Antokan. 


\section{RUMUSAN MASALAH}

1. Seberapa besar prediksi tekanan penduduk terhadap lahan di subdas Antokan Kecamatan Tanjung Raya KABUPATEN Agam

2. Seberapa besar prediksi tingkat kesejahteraan penduduk di subdas Antokan Kecamatan Tanjung Raya Kabupaten Agam

3. Apakah ada suatu sistem pengolahan lahan secara konservasi di subdas Antokan Kecamatan Tanjung Raya Kabupaten Agam

\section{TUJUAN PENELITIAN}

1. Untuk mengetahui prediksi tekanan penduduk terhadap lahan di
subDAS Antokan Kecamatan Tanjung Raya Kabupaten Agam

2. Untuk mengetahui prediksi tingkat kesejahteraan penduduk di subdas Antokan Kecamatan Tanjung Raya

3. Untuk mengetahui ada tidaknya suatu sistem pengolahan lahan yang berkaitan dengan konservasi di subDAS Antokan Kecamatan Tanjung Raya Kabupaten Agam

\section{METODOLOGI}

\section{Waktu dan Tempat}

Penelitian ini telah dilaksanakan di sub DAS Antokan Kecamatan Tanjung Raya, Kabupaten Agam, Sumatera Barat.

(Lokasi: Gambar 1.)

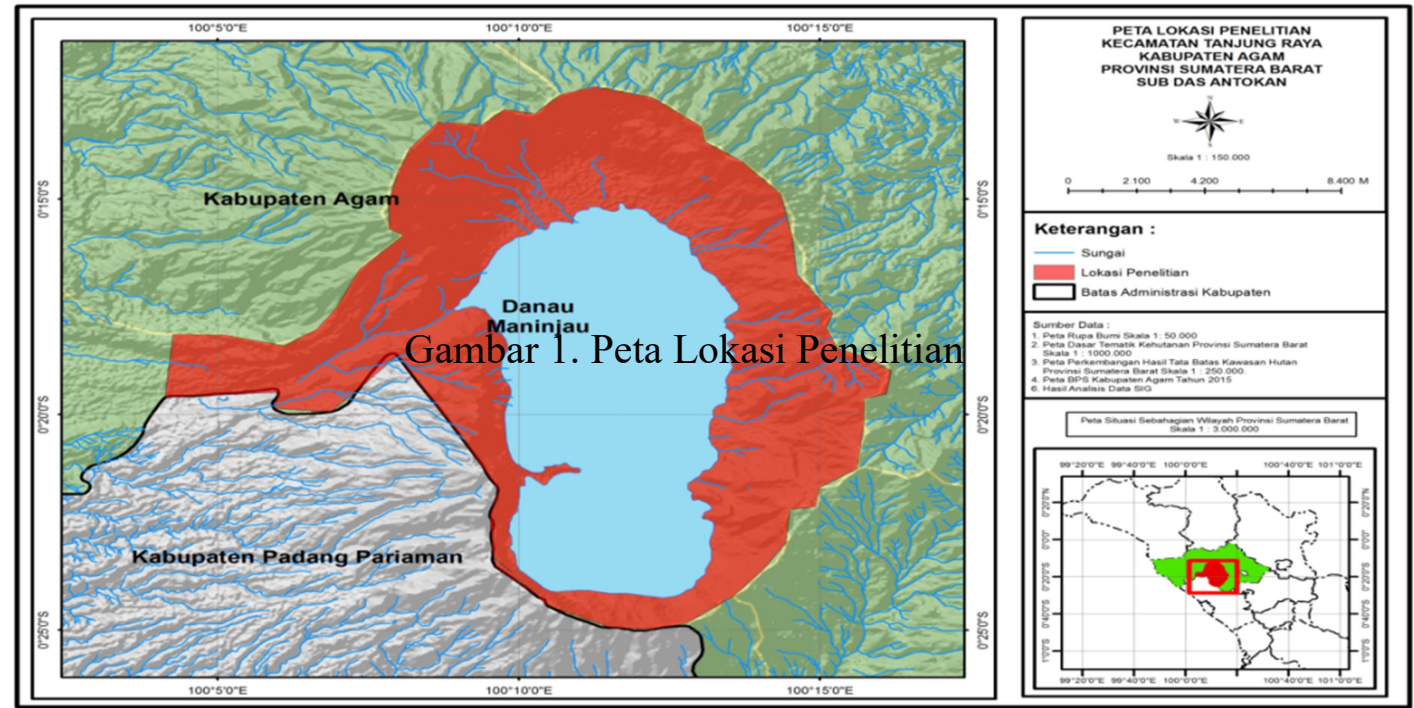

Keterangan :

$\mathrm{TP}=$ Tekanan Penduduk

$\mathrm{Z}$ = luas lahan minimal untuk hidup layak $(\mathrm{Ha})$

$\mathrm{F}=$ perbandingan jumlah petani terhadap populasi penduduk di DAS (\%)

Po $=$ jumlah penduduk pada waktu $\mathrm{t}=0$

$\mathrm{r}$ = laju pertumbuhan penduduk per tahun (orang/tahun)

$\mathrm{t}=$ waktu (periode waktu hitungan misal 5 tahun) (tahun)

$\mathrm{L}=$ luas lahan pertanian di DAS (Ha) 


\section{Alat dan Bahan}

Alat dan bahan yang digunakan selama penelitian adalah Program software ArcGis 10.1 Program Microsoft Office Excel, Alat tulis

\section{Analisa Data}

\section{Tekanan Penduduk}

Metode yang digunakan untuk mengetahui nilai tekanan penduduk mengacu kepada Peraturan Dirjen RLPS Tentang Pedoman Monitoring dan Evaluasi Daerah Aliran Sungai NOMOR : P.04/V-SET/2009

Analisis

$$
\mathrm{TP}=z \frac{f \cdot P o \cdot(1+r)^{t}}{L}
$$

Nilai "Z" diperoleh dari nilai garis kemiskinan yang dinilai setara dengan harga beras yang berlaku pada tahun terakhir dan dari kebutuhan pangan dan hortikultura serta pendapatan petani yang diharapkan yang ada di kawasan sub DAS Antokan Kecamatan Tanjung Raya Kabupaten Agam

Perhitungan tekanan penduduk menggunakan klasifikasi nilai adalah sebagaimana yang tersaji pada Tabel 1:
Tabel 1: Nilai, Kelas, Tekanan Penduduk

\begin{tabular}{ccc}
\hline NO & NILAI TP & KELAS \\
\hline 1 & $<1$ & Baik \\
2 & $1-2$ & Sedang \\
3 & $>2$ & Jelek \\
\hline Sumber : & Peraturan Direktur Jenderal Rehabilitasi \\
& Lahan dan Perhutanan Sosial NOMOR : \\
& P.04/V-SET/2009
\end{tabular}

\section{Tingkat Kesejahteraan Penduduk (TKP)}

Metode yang digunakan untuk mengetahui nilai tingkat kesejahteraan penduduk mengacu pada Peraturan Menteri Kehutanan Republik Indonesia Nomor : P.61 /Menhut-II/2014 Tentang Monitoring dan Evaluasi Pengelolaan Daerah Aliran Sungai. Analisis angka kemiskinan dan pendapatan penduduk menggunakan klasifikasi nilai adalah sebagaimana yang tersaji pada Tabel 2

Analisis

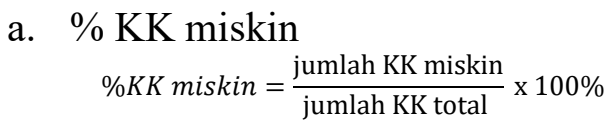

b. Rata-rata pendapatan :

rata - rata pendapatan $=\frac{\text { total pendapatan }}{\text { jumlah penduduk }}$

Tabel.2 Kriteria, Sub Kriteria, Nilai dan Kelas Tingkat Kesejahteraan Penduduk

\begin{tabular}{cccc}
\hline \multirow{2}{*}{ KRITERIA } & SUB & NILAI & KELAS \\
& KRITERIA & TKP $\leq 5$ & Sangat Baik \\
& & $5<\mathrm{TKP} \leq 10$ & Baik \\
& $\% \mathrm{KK}$ & $10<\mathrm{TKP} \leq 20$ & Sedang \\
Tingkat & Miskin & $20<\mathrm{TKP} \leq 30$ & Buruk \\
Kesejahteraan & & $\mathrm{TKP}>30$ & Sangat Buruk \\
Penduduk & & $\mathrm{TKP}>5 \mathrm{jt}$ & Sangat Baik \\
(TKP) & Rata-rata & $4 \mathrm{jt}<\mathrm{TKP} \leq 5 \mathrm{jt}$ & Baik \\
& pendapatan & jt $<\mathrm{TKP} \leq 4 \mathrm{jt}$ & Sedang \\
& & $2 \mathrm{jt}<\mathrm{TKP} \leq 3 \mathrm{jt}$ & Buruk \\
& & $\mathrm{TKP} \leq 2 \mathrm{jt}$ & Sangat Buruk \\
\hline
\end{tabular}

Sumber : Peraturan Menteri Kehutanan Republik Indonesia Nomor : p. 61 /Menhut-II/2014 
Untuk kategori tingkat kesejahteraan penduduk (TKP) jika diperlukan akan divalidasi dengan data primer yaitu dengan wawancara terhadap petani padi sawah.

\subsubsection{Sistem Pengolahan Lahan Secara Konservasi.}

Metode yang digunakan untuk mengetahui nilai tekanan penduduk mengacu kepada Peraturan Dirjen RLPS
Tentang Pedoman Monitoring dan Evaluasi Daerah Aliran Sungai NOMOR : P.04/V-SET/2009

Perhitungan keberadaan dan penegakkan aturan menggunakan klasifikasi nilai adalah sebagaimana taertera pada Tabel 3;

Tabel 3. Kriteria, Parameter, Nilai dan KelasSistem Pengolahan Lahan Secara Konservasi

\begin{tabular}{|c|c|c|c|}
\hline KRITERIA & PARAMETER & NILAI & KELAS \\
\hline $\begin{array}{c}\text { Sistem } \\
\text { Pengolahan } \\
\text { Lahan Secara } \\
\text { Konsesrvasi }\end{array}$ & $\begin{array}{c}\text { Ada tidaknya suatu } \\
\text { sistem pengolahan } \\
\text { lahan secara } \\
\text { konservasi }\end{array}$ & $\begin{array}{c}\text { Ada dipraktekkan luas } \\
\text { Ada dipraktekkan terbatas } \\
\text { Ada tidak dipraktekkan } \\
\text { Tidak ada sistem } \\
\text { pengolahan } \\
\text { Ada tapi kontra konservasi }\end{array}$ & $\begin{array}{l}\text { Sangat baik } \\
\text { Baik } \\
\text { Sedang } \\
\text { Buruk } \\
\text { Sangat } \\
\text { buruk }\end{array}$ \\
\hline
\end{tabular}

\section{HASIL DAN PEMBAHASAN}

\section{Tekanan Penduduk (TP)}

Berdasarkan hasil perhitungan didapatkan nilai takanan penduduk terhadap lahan di subdas Antokan Kecamatan Tanjung Raya Kabupaten Agam adalah 2,57 dengan klasifikasi nilai TP $>2$ dengan kelas Jelek. Hal ini mengindikasikan bahwa di wilayah kawasan subDAS Antokan Kecamatan Tanjung Raya Kabupaten Agam tekanan penduduk terhadap lahan tinggi. Hal tersebut mencerminkan ketidakseimbangan antara jumlah penduduk dan laju pertumbuhannya dengan ketersediaan lahan pertanian

\section{Tingkat Kesejahteraan Penduduk (TKP)}

Berdasarkan hasil perhitungan didapatkan nilai tingkat kesejahteraan penduduk untuk kategori kk miskin adalah 13,8 \%, dengan klasifikasi nilai $10<$ TKP $\leq 20$ dengan kelas sedang. Kategori rata-rata pendapatan nilainya adalah $\mathrm{Rp}$ 9.550.000,-/orang/tahun dengan klasifikasi nilai adalah TKP > 5juta dan kelas Sangat Baik. Setelah divalidasi dengan data primer terdapat perbedaan pendapatan petani yaitu $\mathrm{Rp}$ 11.4.00.000,-

\section{Sistem Pengolahan Lahan Secara Konservasi.}

Berdasarkan hasil wawancara terbuka yang dilakukan di masingmasing Nagari yang ada di kawasan subDAS Antokan Kecamatan Tanjung Raya Kabupaten Agam dan dilakukan pengolahan data, diketahui bahwa sistem pengolahan lahan yang dipakai oleh hampir seluruh masyarakat Kecamatan Tanjung Raya adalah Wanatani dengan jenis pertanaman sela. 


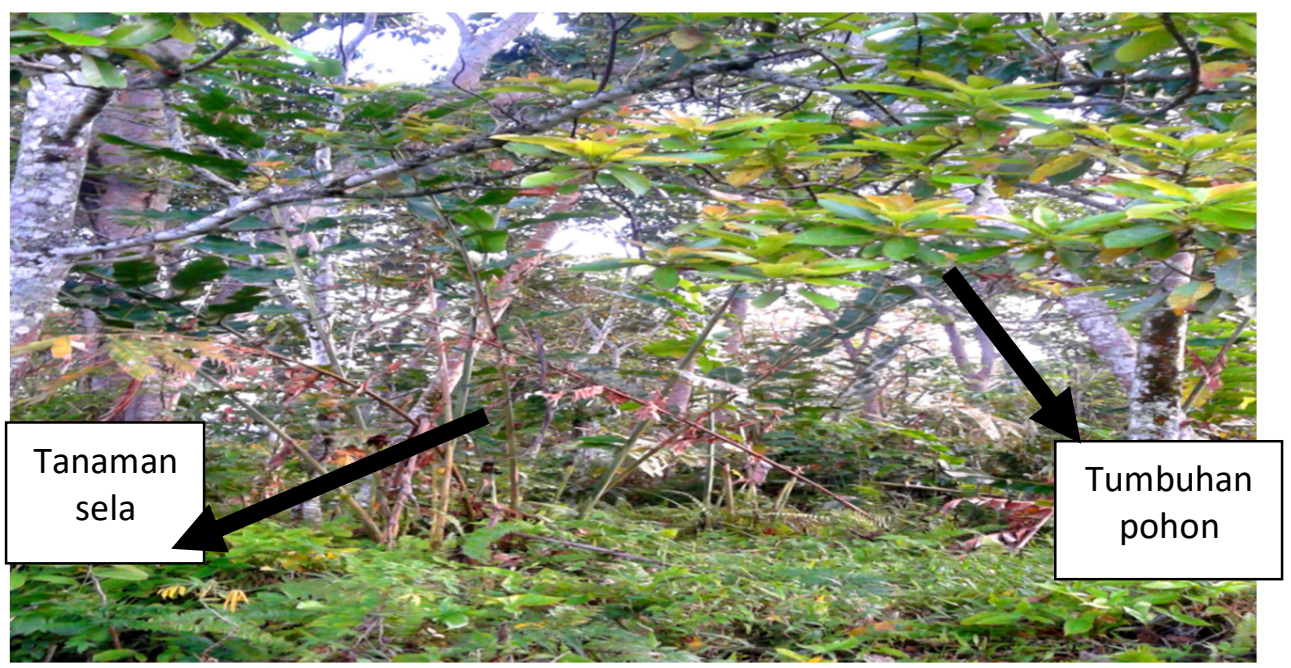

Gambar.2 Sistem pengolahan lahan secara konservasi, yaitu Wanatani dengan jenis pertanaman sela.

Tumbuhan pohon-pohonan yang mendominasi ladang masyarakat di kawasan subDAS ini adalah damar (Agathis dammara), kayu kulit manis (Cinnamomum verum), surian (Toona sureni)

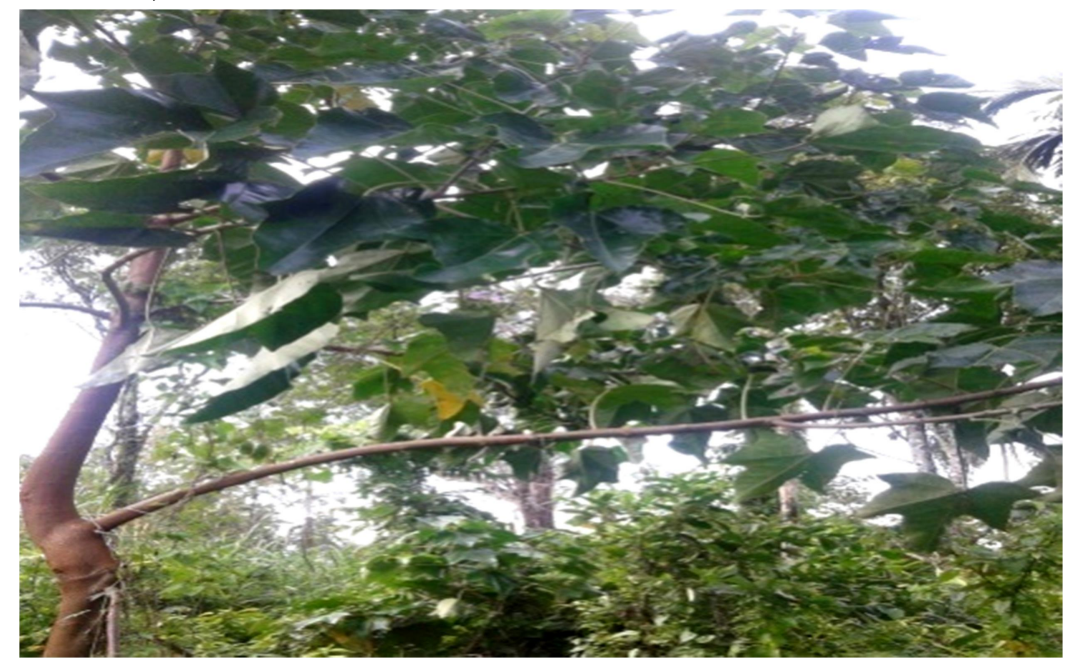

Gambar 3.damar (Agathis dammara)

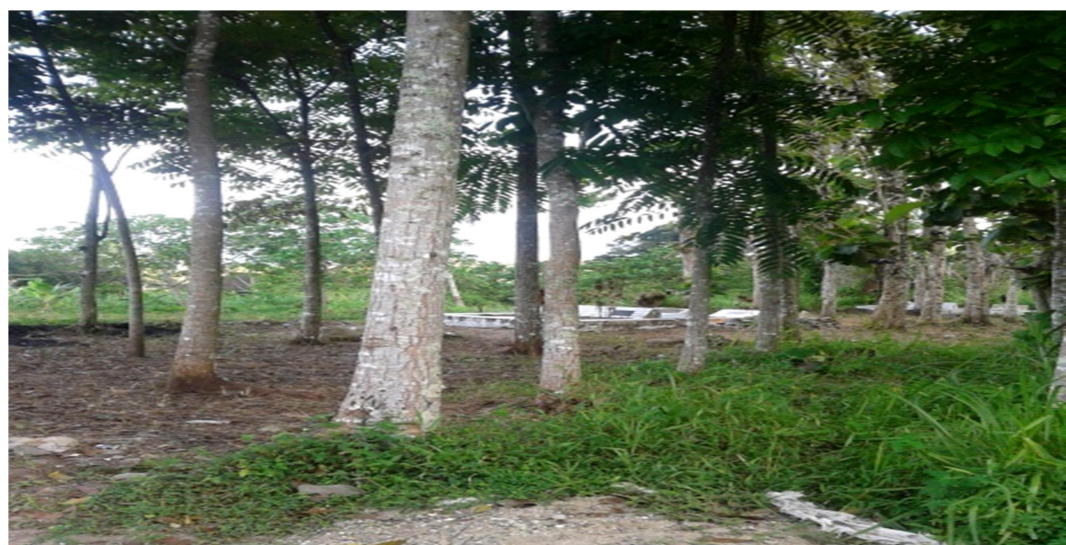

Gambar 4. kulit manis(Cinnamomum verum) 
sedang tanaman sela yang dijumpai adalah pinang (Areca catechu L), lengkuas (Alpinia galanga), jahe (Zingiber officinale), temulawak (Curcuma xanthorriza),

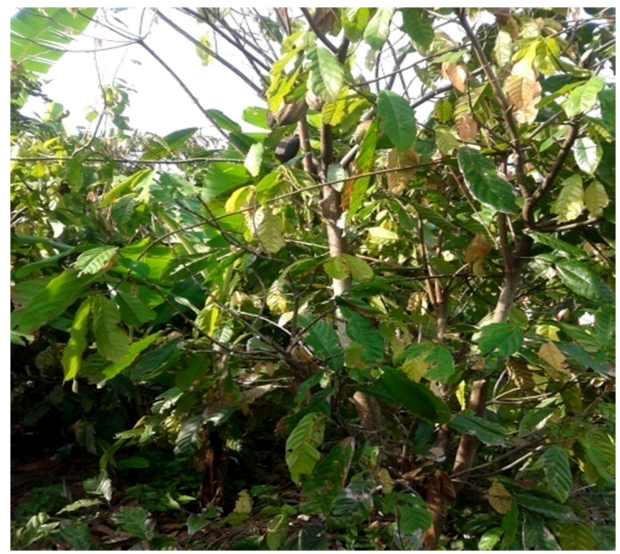

Gambar 5.Kakao (Theobrema cacao)

KESIMPULAN DAN SARAN

\section{Kesimpulan}

1. Nilai tekanan penduduk terhadap lahan pertanian (TP) dikawasan subDAS Antokan Kecamatan Tanjung Raya Kabupaten Agam adalah 2,507 dengan klasifikasi TP $>2$ dan kelas Jelek. Proyeksi jumlah penduduk 5 tahun kedepan menggunakan rumus eksponensial adalah 37.840 jiwa.

2. Nilai tingkat kesejahteraan penduduk (TKP) dikawasan subDAS Antokan Kecamatan Tanjung Raya Kabupaten Agam untuk keluarga miskin adalah adalah $13,8 \%$ dengan klasifikasi nilai $10<$ TKP $\leq 20$ dan kelas Sedang, untuk rata-rata pendapatan adalah Rp 9.550.000,- dengan klasifikasi nilai TKP $>5$ Juta dan kelas Sangat baik.

Berdasarkan hasil wawancara terhadap petani padi sawah, pendapatan petani adalah $\mathrm{Rp}$ 11.400.000,- . Terdapat perbedaan yang cukup jauh antara hasil
kakao(Theobrema cacao), pepaya (Carica papaya), jeruk (Citrus $x$ sinensis)dan pisang (Musa acuminata, M. balbisiana, M. Paradisiaca

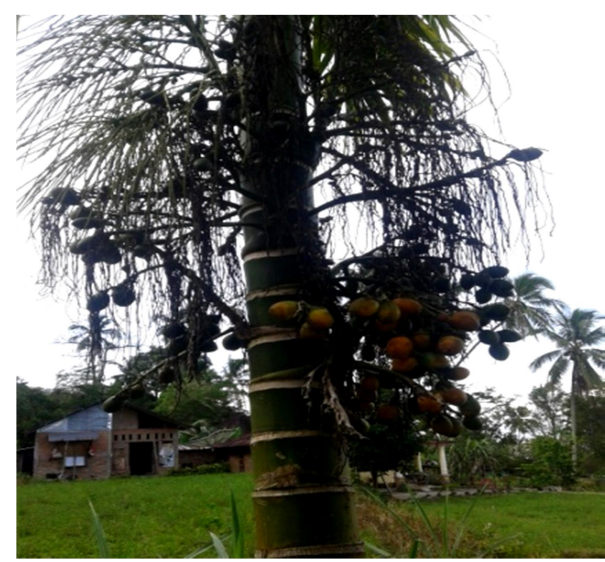

Gambar 6.Pinang (Areca catechu L)

perhitungan dengan hasil wawancara.

3. Sistem pengolahan lahan yang terdapat di subDAS Antokan Kecamatan Tanjung Raya Kabupaten Agam sudah berjalan sesuai kaidah konservasi dengan klasifikasi nilai Ada, dipraktekkan dengan baik, dengan kelas Sangat Baik.

\section{DAFTAR PUSTAKA}

A, Fahmuddin dan Widianto. 2015. Petunjuk Praktis Konservasi Tanah Pertanian Lahan Kering. Bogor : World Agroforestry Centre ICRAF Southeast Asia

\section{BPDASHLAK, 2015. Rencana Pengelolaan Daerah Aliran Sungai Terpadu DAS Antokan 2015-2030. Padang.}

Agus Wuryanta \& Pranatasari Dyah Susanti, 2015, Analisis spasial tekanan Penduduk Terhadap 
Lahan Pertanian di sub DAS

Keduang, Kabupaten

Wonogiri, Jawa Tengah (Spatial Analysis of Population Pressure on Agricultural Land in

Keduang SubWatershed, Wonogiri District, Central Java) Balai Penelitian Teknologi

Kehutanan Pengelolaan Daerah Aliran Sungai, J1.A.Yani, Pabelan PO.BOX 295 KartasuraSurakarta, Indonesia

Chomitz,2006) at Loggerheads?,

Agricultural Expansion, Poverty Reduction, and Environment in the Tropical Forests, International Publication, Vol. I. Report Number 36789. The World Region

Guntoro, S. 2008. Membuat Pakan Ternak dari Limbah Perkebunan. Cetakan Pertama. PT Agromedia Pustaka, Jakarta.

Jones C., P. M. (2002). Watershed health monitoring. Emerging technologies. Washington D.C: Lewis Publiser.

Mawardi,I. 2010. Kerusakan Daerah Aliran Sungai dan Penurunan Daya Dukung Sumber Daya Air di Pulau Jawa Serta Upaya Penanganannya. J. Hidrologi Indonesia Vol.5 No.2 Hal 1-11 Jakarta Agustus 2010. ISSN 1907-1043

[PERDIRJEN RLPS No : P.04/VSET/2009], Kementerian Lingkungan Hidup dan Kehutanan, Jakarta. 2009.
[PERMENHUT, RI NO p.61/MenhutII/2014]. Kementerian Lingkungan Hidup dan Kehutanan, Jakarta. 2014 